\title{
PODE DEUS DETERMINAR O VALOR DE П? (OU, PENSAR NA OBJETIVIDADE DEPOIS DE HEGEL E WITTGENSTEIN) ${ }^{1}$
}

\author{
Hilan Bensusan* \\ hilanb@unb.br
}

RESUMO $O$ trabalho discute alguns elementos comuns nas argumentações de Hegel e Wittgenstein contra a idéia de que objetividade deriva de uma pura receptividade. Discuto o impacto das observações de Wittgenstein sobre o que torna uma maneira de seguir regras correta para a maneira como pensamos em correção, contato com o mundo e verdade. Considero essas observações à luz do modo como Hegel faz uso de algumas idéias de Kant e como este uso ilumina o modo como podemos pensar no contato do nosso pensamento com o mundo. Entram na discussão algumas posições recomendadas contemporaneamente por filósofos como McDowell, Hornsby e Brandom. Termino sugerindo uma maneira de pensar na verdade que não invoca a imagem da adequatio intellectus ad rem e na objetividade que procura levar em conta os argumentos de Hegel e Wittgenstein contra a possibilidade de acesso ao mundo sem a interferência de práticas conceituais.

Palavras-Chave Hegel; Wittgenstein; Objetividade; Verdade; Seguir Regras; Correção

* Professor Doutor do Departamento de Filosofia da Universidade de Brasília. Artigo recebido agosto de 2005 e aprovado em julho de 2006.

1 Este trabalho evoluiu de partes do meu curso no Departamento de Filosofia da Universidade de Brasília sobre aproximações entre Hegel e Wittgenstein. Versões preliminares dele foram apresentadas na ANPOF de 2002, em São Paulo, e em seminários na Universidade de Brasília. Agradeço a Filipe Ceppas e a quem fez um parecer anônimo para esta revista por muitas sugestões. O texto teria ficado bem pior sem elas.

KRITERION, Belo Horizonte, n 115, Jun/2007, p. 47-66. 
ABSTRACT The work discusses some common elements present in the way Hegel and Wittgenstein argue against the idea that objectivity can be understood in terms of pure receptivity. I consider the impact of Wittgenstein observations concerning what makes the following of a rule correct, both for the way we think about correctness and for the contact with the world and truth. I contrast these observations with Hegel's use of some Kantian ideas and how this use brings light to the way we can think about the contact of our thought with the world. In the course of the elaboration of a position that could take Hegel's and Wittgenstein's arguments, I examine some positions recently recommended by McDowell, Hornsby and Brandom. I finish out by suggesting a way of thinking about truth without appealing to the image of an adequatio intellectus ad rem, and a way of thinking about objectivity that builds on Hegel and Wittgenstein's arguments against the possibility of accessing the world without the aid of conceptual practices.

Keywords Hegel; Wittgenstein; Objectivity; Truth; Rule-Following; Correction

(...) podemos conceber também um entendimento intuitivo (negativamente, quer dizer, simplesmente enquanto não-discursivo), que não passe do geral ao particular e assim ao singular (por conceitos) e para o qual não existiria a contingência do acordo da natureza com o entendimento (...), temos uma tarefa que não podemos cumprir senão por meio de um acordo das qualidades naturais com nossa faculdade de conceitos, acordo sempre contingente, mas de que o entendimento intuitivo não necessita (Kant, KU 77).

Suponha que as pessoas continuassem a calcular a expansão de $\pi$. Então Deus, que sabe tudo, sabe se eles chegarão a '777' antes do fim do mundo. Mas pode esta onisciência decidir se eles chegariam a esta sequiência depois do fim do mundo? Não pode. Quero dizer: Mesmo Deus só pode determinar alguma coisa matemática fazendo matemática. Mesmo para ele a mera regra de expansão não pode decidir o que ela não decide para nós (Wittgenstein, RFM, VII-41).

1. Freqüentemente, queremos dizer que nossos pensamentos são de alguma forma influenciados pelo mundo e não são, portanto, puras construções que resultam de nossos consensos ou de nossas práticas meramente convencionadas. Queremos dizer que de alguma forma alguns de nossos pensamentos fazem contato com o mundo e por isso mesmo são, sob certo aspecto, melhores que outros. Queremos dizer que alguns pensamentos, e 
não todos, têm a propriedade de serem objetivos, ou seja, de responderem ao mundo. Esse anseio de poder dizer algo assim moveu grande parte do esforço filosófico de tornar inteligível nosso contato com o mundo. A tarefa de tornar inteligível a objetividade de alguns pensamentos não é exatamente a tarefa de determinar o que há - estabelecer acerca de que coisas devemos ser realistas -, ainda que esbarre com ela. Nós podemos, pelo menos, imaginar argumentos que procurem convencer de que alguma coisa existe ainda que nós não possamos estar sob a influência dela, e a história da filosofia está cheia de posições em que o ceticismo é exorcizado com ungüentos anti-realistas. ${ }^{2}$ Contudo, o problema da objetividade esbarra na questão acerca do que existe: restrições do mundo sobre nossos pensamentos só podem ser entendidas a partir de uma concepção acerca do que há no mundo - aparece assim o tema dos realismos.

Nesse quadro, a objetividade do pensamento é entendida como uma influência do mundo sobre alguns de nossos pensamentos que constituem uma espécie de receptáculo da influência normativa do mundo sobre nós. Este trabalho pretende explorar as conseqüências de um conjunto de críticas em que algum item pensado possa ser imediato, desenvolvidas primariamente por Hegel na Fenomenologia do espírito e por Wittgenstein nas Investigações filosóficas, para a nossa concepção de objetividade dentro desse quadro. Um conjunto de argumentos desses filósofos parece colocar em xeque as bases da maneira como muitas vezes pensamos a objetividade. Sirvo-me, então, do trabalho de McDowell para explorar algumas alternativas diante dessas críticas. Essa exploração me leva a uma discussão sobre a transcendência da verdade.

Hegel e Wittgenstein são dois filósofos muito diferentes, mas que algumas vezes argumentam na mesma direção. Gostaria de contribuir um pouco para colocá-los, de alguma maneira, no mesmo barco. Tentar trazê-los a uma mesma discussão é o começo de um esforço em pensar como diferentes tradições em filosofia podem contribuir para iluminar um tema central como o tema da

2 Os casos são muitos. Podemos começar pensando no idealismo empírico cum realismo transcendental de Berkeley. Não há nada para além daquilo que é o objeto da nossa experiência (realismo transcendental), e, portanto, qualquer argumento cético que tente colocar uma cunha entre o que nós dizemos que há e o contato que nós temos com o que há fica descartado. Kant, se entendido de uma certa maneira que Allison (1983) por exemplo rejeitaria, parece querer defender que nós não estamos em contato com as coisas mesmas - as coisas mesmas são distintas daquilo que é objeto do nosso conhecimento (idealismo transcendental) e assim não há como argumentos céticos afetarem nossa convicção sobre o que conhecemos. Kant então pode combinar um realismo quanto às coisas mesmas com uma rejeição de qualquer objetividade do nosso pensamento empírico. Uma rejeição das coisas-em-si - ou melhor, da distinção transcendental - nos deixaria inteiramente imunes ao ceticismo. Um anti-realismo poderia inspirar um passo assim, mas penso que a rejeição da distinção transcendental nos deixa muitas alternativas além do anti-realismo. 
objetividade. Creio que as diferenças - considere a diferença entre diagnosticar uma dialética do pensamento e propor que a filosofia esteja desprovida de esforços teóricos - são, pelo menos vistas sob certos ângulos, imensas. E, no entanto, um diálogo e uma convergência são ainda possíveis. Nos últimos anos, alguns filósofos têm se dedicado a mostrar como argumentos de Hegel podem tornar-se mais persuasivos (e relevantes) à luz de certas observações de Wittgenstein (cf. Lamb, 1980; Brandom, 1999). Lamb fez um trabalho pioneiro de encontrar doutrinas comuns entre as maneiras como Hegel e Wittgenstein entendiam as conexões entre percepção e linguagem. Em uma certa medida, McDowell mesmo, em trechos de seu Mind and world (1994), insinua alguns pontos em comum entre a forma com que Hegel concebe os conceitos e o modo como Wittgenstein tende a desconfiar de uma suposta incapacidade de nossos significados de alcançarem o mundo. Este trabalho, em certa medida, procura ser parte desse esforço de aproximação.

2. Uma maneira tradicional de pensar na objetividade envolve a idéia do que Kant chamaria de receptividade pura. A receptividade é não mais que uma capacidade de contato com o mundo, e a tese de sua pureza requer que ela possa ser exercida em completo isolamento das nossas faculdades de pensamento - a espontaneidade. Quando a espontaneidade não contribui, nós apenas recebemos aquilo que o mundo nos oferece. A idéia de uma receptividade pura está no centro de muitos modos tradicionais de pensar acerca do mundo e como entramos em contato com ele. Ela está tradicionalmente associada à tese de que intuições prescindem de conceitos para terem conteúdo - graças à crítica de Kant de que intuições sem conceito seriam cegas. Hegel entendeu que Kant não parece poder ver todas as conseqüências de sua denúncia. Ele ainda pareceria ser refém da idéia de uma receptividade pura quando admite que podemos conceber um entendimento intuitivo que não dependeria de um acordo sempre contingente entre as qualidades naturais e os nossos conceitos (cf. epígrafe anterior). Ainda que Kant considere que, em nós, a receptividade sempre aparece embrenhada de nossas formas de percepção, nossas categorias e nossos conceitos, nós podemos imaginar um entendimento para o qual intuições podem aparecer sem conceitos. Intuições sem conceito - Hegel pensa que devemos concluir com Kant - são apenas cegas para nós, não para qualquer intelecto. Hegel entende que a idéia de um entendimento ou de um intelecto intuitivo revela que a receptividade está apenas contingentemente associada aos elementos do nosso pensamento e que nosso intelecto, onde a receptividade está contaminada, não pode senão frustrar as expectativas de que nossa receptividade traria alguma esperança de objetividade aos nossos 
pensamentos. A mensagem de Kant, é claro, pode ser ouvida como uma mensagem de humildade: nosso intelecto, e todo intelecto que possa vir a ser o objeto do nosso conhecimento, é um intelecto de segunda classe, incapaz de ter uma receptividade suficientemente purificada. Mas essa mensagem de humildade depende da receptividade pura ser possível - e note-se que, sem receptividade pura, as coisas-em-si, o locus da objetividade, parecem não poder ser mais do que nomes de uma completa impossibilidade.

Este diagnóstico de que nós somos incapazes de qualquer exercício puro de receptividade - de receber o que está lá para ser recebido - parece fazer com que nossas capacidades cognitivas sejam incorrigivelmente subjetivas. Este foi o diagnóstico de Hegel: Kant confina as categorias das quais nossa receptividade faz uso à mente subjetiva. Hegel pensa que o problema com Kant foi não ter entendido que a conexão entre intuições e conceitos era uma conexão intrínseca e, portanto, necessária - Kant via a junção entre intuições e conceitos, em nós, como sendo "apenas externa, superficial, tal como um pedaço de madeira e uma perna podem estar conectadas por uma corda" (LHP, p. 441).

Hegel tenta pensar a receptividade como sendo intrínseca e necessariamente conectada com conceitos; ao tirarmos os conceitos daquilo que recebemos, perdemos conceitos $e$ objeto. Kant teria hesitado diante de uma conexão mais íntima entre receptividade e espontaneidade por não ter podido se livrar do modo tradicional de pensar a objetividade: a espontaneidade, mesmo que seja o que permita que a receptividade opere, é um ruído na comunicação com aquilo que, sem ela, está lá. A espontaneidade é como um telescópio que precisamos para ver o que se passa, mas que distorce o que queremos ver. Hegel entende que romper com esse modo de ver a objetividade implica em recusar a idéia de que as categorias do nosso pensamento funcionam como um instrumento que pode ser estudado, pelo menos pode ser estudado por alguém com alguma coisa como um intelecto intuitivo, como estudamos o telescópio e estimamos a distorção que ele produz. Hegel pensa que a idéia de conhecimento como um instrumento dá origem à concepção de que, de algum modo, nossos conceitos distorcem as coisas mesmas. Nosso meio distorce o que queremos apreender e depois só nos resta tentar compensar a distorção tão bem quanto seja possível pois

parece possível remediar esse inconveniente pelo conhecimento do modo de atuação do instrumento, o que permitiria descontar no resultado a contribuição do instrumento para a representação do absoluto que por meio dele fazemos; obtendo assim o verdadeiro em sua pureza. Só que esta correção nos levaria, de fato, onde antes estávamos. Ao retirar novamente, de uma coisa elaborada, o que o instrumento 
operou nela, então essa coisa (...) fica para nós exatamente como era antes desse esforço; que, portanto, foi inútil (PhG, p. 73).

O conhecimento não é alguma coisa que necessita de um instrumento; Hegel tenta alcançar uma imagem do conhecimento em que os conceitos aparecem não como elementos que distorcem o objeto, mas como fatores que o constituem. Se sem conceitos, nada pode ser pensado, os objetos antes da intervenção dos conceitos não apenas não fazem diferença no nosso pensamento como não podem ser constituídos de forma alguma. A rejeição da idéia do conhecimento como um instrumento nos faz desembocar na rejeição de qualquer possibilidade de receptividade pura.

3. A idéia de Hegel é a de rejeitar a imagem mesma que baliza o modo tradicional de pensar a objetividade. A imagem é que a objetividade só pode encontrar um locus para além de nossos conceitos; o que torna um pensamento objetivo é alguma coisa que está para além do escopo de todo pensamento. A imagem tradicional, denunciada por Hegel, é uma imagem na qual o pensamento só pode especificar seus conteúdos por meio de conceitos mas o conteúdo só pode ter contato com o mundo se, de alguma forma, pudermos corrigir a distorção que os conceitos promovem. ${ }^{3}$ Precisamos do tal acordo contingente entre nossas faculdades conceituais e as qualidades naturais, elas mesmas alheias aos conceitos. Na imagem tradicional há algo lá, capaz de tornar nossas frases e crenças verdadeiras mas independentes de nossas práticas conceituais, e nós aqui, querendo descobrir o que há. Wittgenstein parece denunciar essa mesma imagem quando escreve assim:

Acontece que nossa mente parece nos pregar uma peça estranha. (...) "Na expansão decimal de $\pi$, ou aparece ' 7777 ' ou não - não há outra possibilidade”. Seria dizer: "Deus sabe - mas não nós". Mas o que isto significa? Usamos uma imagem; a imagem de uma série completa que é vista por alguém mas não por outra pessoa. A lei do terceiro excluído diz: "deve ser assim ou não". Então - e isto é um truísmo - ela não diz nada mas nos dá uma imagem. E o problema não deve ser: a realidade está de acordo com a imagem ou não. A imagem parece determinar o que devemos fazer mas ela não faz isto pois nós temos que saber como ela é aplicada. Aqui, dizer "Não há uma terceira possibilidade" ou "Mas não há uma terceira possibilidade"

3 A imagem que baliza a idéia de que a objetividade deve estar para além de nossos conceitos parece estar bem descrita por Bernard Williams (1978). Ali, ele apresenta a noção do que seja a concepção objetiva do mundo para além de qualquer ponto de vista - livre, por exemplo, de qualidades secundárias. Williams reconhece que uma descrição do mundo de um modo livre de qualquer ponto de vista faz uso de conceitos, mas insiste que esses conceitos não são, em algum sentido, apenas nossos. A idéia que emerge é que nossa investigação está gradativamente se depurando dos elementos que são próprios dela. 
expressa nossa incapacidade de tirar os olhos da imagem: uma imagem que parece conter o problema e a solução ainda que todo o tempo nós sintamos que não é assim (PU, p. 352).

A imagem é de alguma coisa que espera nossa investigação para ser revelada; em seguida pensamos que precisamos encontrar um modo de ser fiel à série que existe e evitar qualquer interferência de nossas práticas de cálculo, de nossas categorias, enfim, do nosso processo de pensamento. Libertados dessa imagem, nós temos apenas que nos agarrar ao modo como nós entendemos, em nossa prática matemática ${ }^{4}$ ordinária, o que significa perguntar se '7777' aparece em $\pi$. Wittgenstein diagnostica:

Parece claro que nós entendemos o significado da questão “Aparece 7777 no desenvolvimento de $\pi$ ?". É uma sentença da linguagem coloquial; pode-se mostrar o que significa dizer que 415 ocorre no desenvolvimento de $\pi$; e coisas similares. Bem, nossa compreensão da questão alcança apenas até onde, alguém pode dizer, alcançam estas explicações (PU, p. 516).

Quando abandonamos o modo tradicional de pensar na objetividade e insistimos, como McDowell freqüentemente faz, ${ }^{5}$ que a contribuição da receptividade não pode ser sequer nocionalmente separada na cooperação com a espontaneidade, tendemos a achar que nossos pensamentos estão alheios a qualquer influência vinda do mundo. McDowell aponta para uma disposição de oscilarmos entre tentar limitar o escopo da crítica a qualquer forma de receptividade pura de um lado - defender alguma forma de certeza intuitiva, por exemplo, defendendo espécies de conteúdo não conceitual -, e perder a

4 O exemplo de Wittgenstein trata de como seguimos regras matemáticas. As regras matemáticas são exemplos de regras em geral que precisamos usar para exercer capacidades conceptuais e fazer julgamentos acerca de como são as coisas.

5 McDowell (1994) pensa que podemos isolar exercícios da espontaneidade das ocorrências da receptividade. Isso se deve à sua concepção da experiência como sendo um exercício passivo de nossas capacidades conceituais - é na experiência que se encontra o locus da receptividade, nunca pura. Brandom (1998), por exemplo, pensa que esse recurso à passividade da experiência estruturada e anterior ao exercício do julgamento - espontaneidade pura - é a pior das alternativas para alcançar o que McDowell pretende; ou seja, uma concepção da objetividade que não precise apelar para qualquer forma de dado e que não nos deixe a impressão de ser um embuste anti-realista. Brandom rejeita que nas experiências são as únicas ocasiões em que a espontaneidade e a receptividade estão indissociavelmente combinadas - se for assim, há exercícios conceituais onde há maior presença de receptividade que em outros. Brandom diz que para McDowell "experiências são entendidas como sendo elas mesmas estruturadas conceitualmente e portanto como servindo de justificações dos julgamentos perceptuais que elas trazem à baila. Este é um modo de satisfazer o requisito [de escapar da oscilação] mas nós não precisamos adotar este caminho. O passo desde a necessidade de escapar da oscilação em direção à necessidade de experiências conceitualmente estruturadas antes dos julgamentos é um non sequitur (...). Nós não somos informados acerca do que justifica o passo da necessidade de restrições racionais por parte do mundo para restrições racionais por parte da experiência." (1998, p. 373, grifos no original) 
esperança de que nossos julgamentos sofram alguma restrição por parte do mundo - como uma postura anti-realista ou aquilo que Hegel chamou de estoicismo. ${ }^{6}$ De um lado da oscilação somos atraídos para a imagem de que há em algum lugar para além de nossas práticas de cálculo o valor de $\pi$, a série completa que qualquer intelecto capaz de receber com pureza séries infinitas pode contemplar. De outro lado, há o temor de que $\pi$ não seja mais que um figmento da nossa construção social, produto das muitas regras implementadas por meio de sanções e prêmios. Se nos convencemos que há algo profundamente ilusório com a idéia de receptividade pura e com as imagens que a acompanham, nos desesperamos com nossos pensamentos parecerem produtos de uma espontaneidade irrestrita. Se julgarmos que uma tal falta de restrição é intolerável, somos postos a tentar encontrar algum modo de nos sentir confortáveis com a receptividade pura.

Wittgenstein apresentou um conjunto de argumentos que apontam na direção de que regras não determinam nenhuma ação ou nenhum episódio de pensamento - qualquer ação, qualquer episódio de pensamento pode ser posto de acordo com qualquer regra. Ao contrário do que parece, quando aprendemos uma regra -, por exemplo, a regra de somar 2 a um número natural ou a regra para calcular o algarismo seguinte de uma série como $\pi$ - não adquirimos uma interpretação que nos dirá como proceder em cada caso; muitos diferentes procedimentos podem ser apresentados de modo a estarem de acordo com a regra, não importa quão bem especificada ela esteja. Segue-se que não há um elemento do mundo que seja precisamente especificado por uma regra sozinha - isto é, sem a nossa compreensão dela. É certo que interpretamos regras, mas essas interpretações são como os protótipos mentais que fazemos dos termos que usamos - irrelevantes. Não há um fato separável de nossa compreensão que seja especificado pela regra - não há nada ali em um mundo exterior às nossas regras, aos nossos conceitos e à nossa capacidade de compreensão que balize o modo como nós seguimos regras. O cerne da questão pode ser entendido como sendo sobre a existência de fatos semânticos que sejam responsáveis pelo modo como usamos nossos termos e aplicamos nossas regras. Se há tais fatos, nós podemos dizer que o que chamamos de

6 McDowell (1994) enxerga, nesse segundo ramo do dilema, também a posição de Davidson (1983, por exemplo) uma vez que a pressuposição de verdade em favor de um conjunto de crenças rejeita qualquer papel para a experiência na formação de nossas crenças. Hegel (PhG, p. 200) entende estoicismo respondendo que é apenas na racionalidade que deve consistir o bem e o verdadeiro. De uma maneira geral, esse segundo lado da oscilação se associa com posições que enfatizam a coerência e que não têm recursos para poder falar de visões de mundo. Consulte Bensusan (2002) para uma análise da oposição entre o cético e o descrente. 
"verde" é verde e é por isso que é chamado de "verde" - podemos conceber, então, um modo de especificar o que é verde sem nossos termos, sem nossos conceitos; um intelecto intuitivo poderia simplesmente captar a interpretação da regra. Haveria, em outras palavras, alguma coisa não mediada pelos nossos conceitos e que poderia eventualmente ser objeto de uma receptividade pura. Wittgenstein parece mostrar que não há.

Uma certa interpretação estimulada por Kripke (1982) e abraçada por algumas formas de anti-realismo está disposta a concluir que temos que nos conformar que não há fatos semânticos, simplesmente não há coisas assim; eles não podem ser formulados de um modo que prescinda de nossas regras, conceitos, práticas e compreensão. Segue-se que todos os nossos padrões dependem de nossa ratificação e então devemos recomendar que esqueçamos qualquer esperança de objetividade. Kripke descreve o nosso processo de seguir regras em termos de nossa capacidade de induzir, o que provocará reprimendas -, e assim, apenas com reprimendas, e prêmios, podemos seguir regras, jamais em uma linguagem privada: em uma linguagem assim, o que me parece correto é correto. ${ }^{7}$ Uma interpretação assim dos argumentos de Wittgenstein conecta a existência de fatos - ou a objetividade - à disponibilidade de itens para uma receptividade pura. Nossas reprimendas - e nossa capacidade de individuar o que está sendo sancionado nessas reprimendas - são inteiramente nossas, não sofrem influência alguma do mundo. Estamos em um terreno onde o locus da objetividade deve estar para além de nossos conceitos e regras; estamos diante de uma posição segundo a qual, como diria Hegel, nossas regras são confinadas à mente subjetiva (e à interação social): uma posição kantiana. Se quisermos resistir a uma posição assim, temos que rejeitar uma interpretação como essa que Wittgenstein comenta acerca de seguir regras. Algumas vezes, Wittgenstein parece claramente querer evitar uma interpretação assim; por exemplo, quando ele apela para formas de vida e para costumes que nos fazem seguir sinais (PU, p. 198), ou quando diz que "há um modo de captar uma regra que não é uma interpretação, mas que é exibida no que chamamos de obedecer uma regra e ir contra ela nos casos reais" (PU, p. 201). Parece, nesses trechos, que quando compreendemos uma regra fazemos

7 Kripke pensa que o assim chamado argumento contra a linguagem privada (PU, p. 258-260) é um corolário das observações acerca de seguir regras. Crispin Wright (1986), no entanto, pensa que, se na seção 258, nós subsitituímos "eu" por "nós", temos ainda uma falta completa de objetividade. Segue-se que não sobra diferença alguma entre uma linguagem privada e uma linguagem pública. No entanto, é claro, a distinção entre as duas já nos dá critérios de correção - mais uma vez, muito depende de como concebemos a objetividade. Note também que apenas do exercício sugerido por Wright não poderíamos concluir que não há argumento algum contra uma linguagem privada nas Investigações; argumentos independentes talvez possam ser retirados, entre outros, da região em torno da seção 342. 
mais do que um conjunto de induções para evitar reprimendas; podemos capturar o conteúdo de uma regra desde que estejamos inseridos em um conjunto de práticas que nos torna competentes na linguagem.

Uma interpretação alternativa das observações de Wittgenstein enfatiza que talvez não precisemos abandonar a idéia de fatos semânticos completamente apenas porque eles dependem de nossa compreensão. ${ }^{8}$ Se rejeitarmos o elo tradicional entre o que é passível de surgir em um episódio de receptividade pura e o locus da objetividade, podemos entender fatos semânticos como sendo especificáveis apenas por meio de nosso esforço de compreensão dentro de uma prática na linguagem - "nós, e os nossos significados, não alcançamos nada menos do que os fatos" (PU, p. 95). McDowell $(1984,1994)$ insiste que podemos continuar a falar que nossos conceitos têm um conteúdo conquanto não possamos esperar que esse conteúdo esteja disponível em algum imaginável episódio de receptividade pura. O nosso mundo, ordinário e não redutível a uma estrutura que possa ser objeto de receptividade pura, pode ser concebido como tendo aquilo que nós comumente pensamos que ele tem: árvores, virtudes, galáxias, regras e números irracionais. Como diz a seção PU 516, citada anteriormente, nossa compreensão alcança apenas onde alcança a nossa linguagem e não temos razões para imaginar que há algo mais para ser alcançado a não ser que estejamos presos à imagem que sustenta o modo tradicional de pensar na objetividade. Não há nada semântico que possa ser determinado sem que tenhamos que fazer semântica - compreender como faremos para seguir regras -, mas isso não quer dizer que não haja fatos semânticos. Mais do que isso, mesmo Deus, e mesmo um intelecto intuitivo, não pode determinar nada matemático (ou semântico) sem fazer matemática - sem compreender as regras -, diz a epígrafe RFM VII-41. Na verdade, não há nada a ser dito para um intelecto intuitivo - intuições sem conceitos, diz McDowell (2000), são mudas. Uma interpretação assim das observações de Wittgenstein nos leva a abandonar a imagem de que há algo determinado - visível para Deus ou para um intelecto intuitivo - pronto para ser descoberto. Abandonar essa imagem, familiar e persuasiva como ela muitas vezes parece, nos faz pensar que o locus da objetividade pode estar entre os nossos conceitos e nossas práticas e não alhures. Quando conseguimos pensar na objetividade dessa maneira, muitas alternativas se abrem: Qual poderia nos trazer maior conforto?

8 Penso que a noção de compreensão, distinta de interpretação, como a base de nossa capacidade de seguir regras, é a interferência de nossos conceitos e dos materiais do nosso pensamento em tudo aquilo que faz sentido conceber como passível de recepção - em outras palavras, aquilo que Hegel (PhG, cap. 3) chamou de mediação e que descobrimos ativo naquilo que consideramos em geral incondicionado e apenas a ser percebido (recebido) por nós. 
4. Uma alternativa que parece estar ao alcance da mão é entender que o conteúdo de nossos pensamentos é feito daquilo mesmo que é feito o mundo nossos conceitos podem envolver o mundo todo. Em outras palavras, no mundo há pensáveis, e os pensáveis, por meio de conceitos, constituem o mundo. Em um movimento aparentemente próximo dos de Hegel, McDowell recomenda uma posição segundo a qual não há nenhuma distância ontológica entre os fatos e os conteúdos dos nossos pensamentos. Nossos pensamentos são objetivos se eles têm um conteúdo - que só pode ser especificado por aqueles que têm competência nas nossas práticas lingüísticas - que, de alguma forma, pertence ao mundo, a esse mundo que é feito de pensáveis. Quando temos razões para pensar que isto ou aquilo é o caso, estamos considerando os materiais que constituem o mundo - os conceitos. Afirmar que há um mundo entre nossos conceitos pode começar a tornar inteligível a idéia de objetividade sem que precisemos apelar para qualquer forma de receptividade pura. É o que nos afasta da posição que Hegel denominou estoicismo: nosso pensamento é entendido como tendo conteúdo e esse conteúdo pode ser o mundo ele mesmo. Uma maneira de tentar nos acostumar com esse modo de pensar na objetividade é considerar o predicado de verdade. $\mathrm{O}$ modo tradicional de pensar na objetividade apresenta um grande conforto, entendendo a verdade como uma forma de correspondência entre fatos e crenças. Os fatos estão de alguma forma disponíveis para serem objeto de uma receptividade pura e, como Davidson (1983) lembra sempre, a motivação principal para uma concepção da verdade como correspondência é que ela pode fazer sentido em uma confrontação entre o que pensamos e os fatos. ${ }^{9}$ Jennifer Hornsby (2001) sugere que posições como a de McDowell - de que os fatos são feitos de pensáveis - encorajam uma teoria da verdade como identidade.

No entanto, se Hornsby está certa - e uma concepção assim é encorajada por McDowell - então devemos admitir que alguma coisa deve ter saído errada. De acordo com uma teoria da verdade como identidade, um pensamento é verdadeiro se ele é idêntico a um fato. A verdade como identidade, que parece ter sido aventada e recomendada por Frege (1918), concebe que a identidade é o elo entre crenças e fatos e, portanto, não apresenta os problemas das concepções correspondentistas. ${ }^{10}$ Fatos, podemos dizer, são pensáveis; com respeito

9 Consultar Bensusan (2003) para uma análise de algumas teorias da verdade contemporâneas com respeito ao problema da objetividade.

10 Por exemplo, o argumento do moinho, de Frege. $\mathrm{O}$ argumento diz que é preciso que a crença $\mathrm{C} 1$, de que uma crença $\mathrm{CO}$ corresponde a um fato ela mesma, corresponda a um fato; para isso é preciso uma crença $\mathrm{C} 2$ de que uma crença $\mathrm{C} 1$ corresponde a um fato etc. Ao contrário da hierarquia de linguagens exigida por uma concepção de verdade à la Tarski, uma concepção assim apela para uma implausível hierarquia infinita de fatos. 
à distribuição de partículas que fariam com que o pensamento "O outono começou" seja verdadeiro, Hornsby diz que "itens como a distribuição cósmica de partículas estão no mesmo barco [que itens como o outono]: não podem ser usados na reconstrução dos pensáveis a partir de alguma outra coisa" (2001, p. 671, tradução minha). A teoria da identidade é uma teoria que diz respeito a um sucesso - quando atingimos os fatos com nossos pensamentos, então pensamos com verdade. Portanto, e isso me parece importante, ela também é uma teoria da verdade como adequação; ou seja, um pensamento precisa estar adequado (idêntico) a um fato para ser verdadeiro. O problema com teorias da adequação é que elas sempre sugerem que há fatos em alguma parte que vão determinar a verdade de nossos pensamentos. É claro que, se nosso objetivo é nos assegurar de que os nossos pensamentos não são indiferentes ao mundo, uma concepção assim parece bastante bem-vinda. E, contudo, podemos desconfiar que uma concepção assim necessita que haja conteúdos que ainda não foram pensados - fatos, feitos de pensáveis - e que, ainda assim, estão em alguma parte prontos para serem pensados. Podemos desconfiar que poderíamos imaginar um intelecto especial - podemos conceber Deus como quisermos - que possa receber aquilo que nós estamos recebendo apenas graças ao concurso de nossos conceitos. Não seria, é certo, o mesmo tipo de intelecto intuitivo que Kant imaginou, pois esses fatos são feitos de pensáveis, não são receptíveis sem conceitos, mas ainda assim podemos experimentar uma frustração muito parecida com aquela que muitos experimentam quando Berkeley diz que Deus percebe o que nós (ainda) não percebemos. Fica parecendo que deve ter havido alguém a promover o trabalho dos conceitos de modo a que o pensável tenha se tornado pensável antes de nós começarmos a poder pensar com verdade - a adequar nosso pensamento aos pensáveis que constituem o mundo. Em termos hegelianos, fica parecendo ou que os fatos são pensáveis, mas imediatos ou que alguém de alguma forma os mediou. Hegel teria uma concepção da verdade diferente de qualquer concepção de adequação - a verdade surge sempre de um trabalho conceitual que recebe restrições da parte do ainda não pensado. Neste "ainda não pensado" não reside de forma alguma a fonte da verdade, uma vez que ali não pode estar o locus da objetividade. $\mathrm{Na}$ teoria da verdade como identidade, por outro lado, parece que o que pode fazer nossos pensamentos verdadeiros são fatos conceituais mas que podem não ter sido pensados.

Estaríamos assim retornando a uma maneira de pensar que nos deixa confortáveis porque apela para as imagens familiares de algo que fica à espreita para fazer nossos pensamentos objetivos? Fica parecendo que é preciso que Deus tenha calculado $\pi$ antes de todos nós para que nossas afirmações sobre $\pi$ 
possam ser verdadeiras; mesmo que Deus tenha que ter feito matemática para isso. O problema é que se Deus fez matemática antes de nós, então há uma maneira correta - a de Deus - de interpretar as regras que seguimos quando calculamos os algarismos que compõem a expansão de $\pi$. Wittgenstein diria que a verdade não pode ser alguma coisa como adequação se realmente rejeitamos a imagem que sustenta a possibilidade de uma receptividade pura. Nesse ponto, podemos nos desesperar e desistir da objetividade: apenas nossos conceitos determinam o que pensamos; puro estoicismo. Parece que se rejeitamos a imagem de uma seqüência que compõe, por exemplo $\pi$, e que seja determinada apenas por uma regra que possa ser formulada como uma regra de expansão - isto é, se acreditamos que nenhuma regra de expansão será suficiente para determinar sozinha os algarismos que compõem $\pi$-, então temos que rejeitar que haja algo para além de nossas práticas (matemáticas, investigativas ou semânticas) que nossas práticas tentam alcançar. Parece que qualquer concepção de verdade como sendo uma forma de sucesso em atingir uma adequação de nosso pensamento à algo fora dele tem que ser abandonada e isso nos leva a indagar como e por que ainda insistiríamos em querer falar de objetividade.

5. Parece que a noção de verdade terá que ser entendida de alguma forma diferente daquela que sugere a adequação; de modo que o nosso esforço de produzir juízos seja parte daquilo que torna um pensamento verdadeiro. De alguma forma, temos que substituir a imagem de que estamos diante de alguma coisa que se desvela por um processo de investigação, por uma imagem suficientemente diferente, para que não estejamos mais sob a tentação de almejarmos algum modo de adequação. Se pensarmos na objetividade em termos de conteúdos pensáveis a serem alcançados ou abraçados por nós, estamos próximos de pensar que a objetividade tem seu locus em alguma parte alcançável, se bem que talvez não alcançada por nós. Um modo de pensar assim ainda está balizado na imagem da objetividade residindo para além da cortina costurada pelo que nós acessamos. Hegel diz, ao concluir que a verdade requer mediação de conceitos: "Fica patente que por trás da assim chamada cortina, que deve cobrir o interior, nada há para ver, a não ser que nós entremos lá dentro - tanto para ver como para que haja algo ali atrás que possa ser visto" (PhG, p. 165, grifo meu). 
Podemos tomar esse diagnóstico sobre o que há atrás da cortina, em particular o trecho que grifei, como sendo o núcleo das críticas ${ }^{11}$ que Hegel e Wittgenstein apresentam ao modo tradicional de conceber a objetividade. Se for assim, podemos nos propor a procurar uma imagem que não apele para alguma cortina que nos impede de ver coisas que estão atrás da mesma - e que mediria nosso sucesso pela nossa capacidade de levantar essa cortina.

Antes de tentar construir uma imagem alternativa da nossa busca pela objetividade, vale a pena perguntar se McDowell mesmo não nos poderia tranquiilizar completamente. Isso equivaleria a perguntar se a posição de McDowell seria ela também refém dessa imagem da cortina e portanto das críticas de Hegel e Wittgenstein à concepção tradicional de objetividade. Hornsby diz que a posição de McDowell, segundo a qual pensamentos e fatos são constituídos por pensáveis, apenas encoraja uma teoria da verdade como identidade. Mas McDowell, por sua vez, diz:

Se nós dizemos que deve haver uma restrição ao pensamento vinda de fora dele, de modo a assegurar o reconhecimento da independência da realidade, nós ficamos reféns de um tipo comum de ambigüidade. "Pensar" pode significar o ato de pensar; mas também pode significar o conteúdo de um item de pensamento: o que alguém pensa. Se nós precisamos reconhecer a independência da realidade, o que nós precisamos é de uma restrição vinda de fora do que pensamos e julgamos, nossos exercícios de espontaneidade. A restrição não precisa vir de fora de conteúdos pensáveis. Seria na verdade afetar a independência da realidade se nós igualássemos fatos com exercícios de capacidades conceituais - atos de pensamento - ou representássemos fatos como reflexos de tais coisas (...). Mas não seria idealista (...) dizer que fatos em geral são essencialmente capazes de serem envolvidos por pensamento nos exercícios de espontaneidade (...). A restrição vem de fora do ato de pensar, mas não de fora do que é pensável (1994, p. 28).

McDowell parece confiar que podemos ter restrições feitas de pensáveis aos nossos atos de pensamento - conteúdos pensáveis, mas não pensados, restringem nossos pensamentos. Ainda que ele não se comprometa com uma teoria da verdade como identidade, ele admite que há fatos feitos de pensáveis que devem estar atrás da cortina para que nossos pensamentos possam ser objetivos $^{12}$ - não é que precisamos entrar para que eles existam, eles devem

11 Wittgenstein parece apontar para algo semelhante quando diz que há "duas imagens de uma rosa no escuro. Uma é bem preta, pois a rosa é invisível. Na outra, a rosa está pintada com detalhes e está cercada de preto. É uma destas imagens certa e a outra errada?" (PU, p. 525).

12 A questão aqui é se McDowell está certo em adotar como plausível o que chama de empirismo mínimo. O empirismo mínimo sustenta que a experiência restringe nosso pensamento desde fora, pois alguns conteúdos pensáveis tornam-se pensados com a experiência. Uma posição assim, contudo, parece depender da imagem da cortina. 
existir com independência de onde estamos. Pensáveis ou não, parece que temos, então, que conceber os algarismos de $\pi$ como estando já atrás da cortina, restringindo nossa espontaneidade - quem tudo vê, veria atrás da cortina, e, uma vez visto, há uma regra para se expandir $\pi$ que determina uma única interpretação: aquela que produz aquilo que está atrás da cortina. Fica parecendo que McDowell, admitindo que na experiência nossas capacidades conceituais são exercidas de forma passiva, deve admitir que há alguma coisa que é pensável e que poderia em princípio ser recebida por algum intelecto que enxergasse por trás da cortina. É certo que esse intelecto teria que ser capaz de receber pensáveis - não seria, portanto, um entendimento intuitivo como o que Kant concebeu -, mas seria um intelecto que, independente de nossas práticas conceituais, determinaria o que há por trás da cortina e, portanto, nosso sucesso em ver a coisa certa.

McDowell, portanto, tentou fazer com que pelo menos um eco da idéia de objetividade como resposta a um conjunto de restrições à nossa espontaneidade vindo de fora fosse preservado. ${ }^{13}$ Se uma posição assim não é sustentável, ficamos às voltas com uma noção de objetividade balizada em uma imagem diferente daquela da cortina. Uma sugestão possível pode surgir se substituirmos a imagem espacial de uma cortina que esconde alguma coisa pela imagem temporal de uma investigação que sempre tem um passo seguinte à espera. Pode ser que a passagem do tempo - do tempo entendido primeiramente como uma sequiência de argumentos e contra-argumentos, e não de uma seqüência de eventos quaisquer - é, ela mesma, um modo de investigar

13 O problema central da posição de McDowell talvez esteja não na passividade da experiência, mas na recomendação de um re-encantamento (parcial) da natureza . O re-encantamento assume que fatos - unidades conceitualmente articuladas - possam ser recebidos já prontos. A passividade dos exercícios conceituais que constituem a experiência - e a idéia de um tribunal da experiência e de um empirismo mínimo - levaria McDowell a uma versão da distinção transcendental kantiana que ele quer evitar se não fosse o re-encantamento (e as idéias associadas de segunda natureza, que ele importa de Aristóteles, e de Bildung, que ele importa de Gadamer). Com o re-encantamento, nos relacionamos com um mundo já conceitualmente articulado: há pelo menos uma medida de holismo que precisa ser abandonada (cf. Bensusan; Pinedo, 2006). É interessante considerar o que Crispin Wright (2002, p. 145), em sua resenha de Mind and world, diz sobre a posição de McDowell. Segundo ele, uma posição assim "amounts not to a rejection of the Given as such, but a recasting of it. What is given in experience is essentially of the form: that $P$ - that so-and-so is the case. 'In experience one finds oneself saddled with content' (MW, p. 10). In rejecting the Myth of the Given, McDowell intends to reject a mythology about what is Given, and how, but not the very idea that anything is." [Leva não a uma rejeição do Dado como tal, mas a uma reformulação dele. O que é dado na experiência é essencialmente da forma: que $\mathrm{P}$ - que isto e aquilo é o caso. 'Na experiência nos encontramos já plenos de conteúdo' (1994, p. 10). Ao rejeitar o Mito do Dado, McDowell pretende rejeitar uma mitologia sobre o que é dado e como, mas não a idéia mesma de que alguma coisa seja dada.] Ou seja, McDowell mantém a idéia de que alguma coisa é dada, ainda que esse dado seja conceitualmente articulado. Para uma crítica dessa idéia reformada de dado, cf. Bensusan; Pinedo, 2006. Ali apresentamos uma imagem da objetividade que não está comprometida com a idéia de que certos pensamentos específicos são influenciados pelo mundo. 
as coisas; esse modo de investigação seria um componente do processo em que algo que aparece como outro, como alheio aos nossos conceitos, torna-se acessível às razões. Nossa investigação apresenta a constituição conceitual de todo objeto de nossa investigação. A constituição conceitual, é claro, não é o mesmo que o produto da nossa inteira autonomia porque os conceitos, imersos nas nossas práticas, restringem-se a si mesmos.

A lição de Hegel talvez seja não a de que devemos contrapor ao estoicismo alguma concepção que apelasse para alguma restrição externa aos nossos julgamentos, mas antes a de que devemos entender melhor o que significa dizer que temos restrições internas ao nosso pensamento - o pensamento é restrição suficiente e a única necessária aos nossos julgamentos. Ou seja, Hegel parece estar sugerindo que as nossas práticas conceituais podem ser o locus da objetividade sem que para isso tenhamos que hipostasiar práticas conceituais fora de nosso alcance presente. Dizer que nossas práticas conceituais restringem a si mesmas, é claro, não é dizer que pensamos o que bem entendemos, mas, antes, que as restrições devem ser pensadas dentro de nossas práticas, e isso não as torna, em nenhum sentido, inconvenientes, arbitrárias.

Hegel parece pensar que alcançar a objetividade requer supra-assumir um outro, abarcá-lo em nossas práticas conceituais. Não é que esse outro exista antes de nós; devemos insistir que ele aparece para nós como outro e rejeitar a imagem de um tempo anterior à investigação. Um outro - aquilo que nós não conhecemos - não é nada mais do que um outro; não é, de forma alguma, o locus da objetividade: não há nada que possa ser objetivo antes da investigação. Essa maneira de pensar na objetividade, e de entender a posição que Hegel queria recomendar, está em uma linha frágil. Facilmente podemos pensar que, por exemplo, quando Hegel diz "chamemos conceito o objeto-emsi, e objeto o que é como objeto ou objeto para um outro; então fica patente que o ser-em-si e o ser-para-um-outro são o mesmo" (PhG, p. 166) ele quer dizer que o outro que é o objeto para nós não pode ser mais do que um conceito que aguarda para ser descoberto - parece que ao investigar descobrimos conceitos. Se for assim, estamos de volta a uma concepção que sustenta uma teoria da verdade como identidade e, portanto, como adequação. Penso que é melhor entendermos que o outro só se torna objeto (só se torna conceito) depois de investigado. O tempo futuro é apenas aquilo que comumente entendemos: aquilo que desconhecemos. O tempo futuro não guarda coisa alguma que possa balizar a objetividade; dizer que o mundo é conceitualizável não quer dizer que ele está ali pronto em conceitos para que o pensemos, mas antes que a investigação pode conceitualizar o que aparece - em um dado tempo da investigação - como sendo apenas um outro. 
O locus da objetividade parece ter de estar entre nossas práticas conceituais, uma vez que são elas que balizam os critérios de aplicação de conceitos. Consideremos o que acontece com as dores, os instintos e as tendências de um ponto de vista que critica a idéia de uma linguagem privada. Logo à primeira vista, Wittgenstein parece sugerir ${ }^{14}$ que dores ou, por exemplo, as batidas do coração, não podem produzir por si mesmas quaisquer conteúdos de pensamento, uma vez que não trazem em si mesmas critérios que possibilitem qualquer conclusão. Quando o coração bate mais forte, nos sentimos agitados, ansiosos, inquietos; não é, no entanto, que nos sentimos agitados, ansiosos e inquietos porque o coração bate mais forte. Não é nem mesmo que o coração acompanha nossos sentimentos - se assim fosse, o coração teria que saber quando ficar agitado, ou ansioso, ou inquieto - nós, de alguma maneira, o ensinamos. O coração só põe idéias e sentimentos na nossa cabeça quando aprendemos a falar dele, e aprender a falar do coração é aprender a usar critérios para fazer distinções entre, por exemplo, o coração e os rins. Nós aprendemos a fazer distinções quando aprendemos a falar - vem tudo junto. Não é, portanto, a dor para além do nosso conceito que nos ensina e que estabelece os critérios de identidade do que seja dor - se fosse assim, Deus, ou um intelecto que não compartilhasse de nossas práticas de investigação, poderia já saber quando a dor é dor. Wittgenstein parece portanto sugerir que nossas práticas são soberanas em determinar a aplicabilidade dos nossos conceitos.

6. Essas considerações parecem nos levar firmemente em direção a uma maneira de pensar próxima à que encoraja concepções epistêmicas da verdade e do significado. Uma dificuldade comumente associada a maneiras de pensar desta natureza é que elas não teriam espaço para o erro sistemático e assim não poderiam explicar que aquilo que é objetivo pode transcender nossas atitudes legítimas e nossas crenças justificadas. Trata-se da dificuldade que Hegel via no estoicismo; parece que ficamos confinados em nossos conceitos ou, se quisermos, nos exercícios de pura espontaneidade. Uma maneira comum de lidar com essa dificuldade é apelar para alguma idéia de sabor peirceano de convergência. Uma idéia assim freqüentemente aparece acompanhada da convicção - poucas vezes explicitamente examinada - de que uma progressiva sucessão de produtos de nossa investigação, de alguma maneira, limpa de espontaneidade a nossa aplicação de conceitos e assim, de algum modo, 
convergimos em direção ao que poderíamos seguramente tomar como uma "contribuição pura do mundo em nossa visão do mundo". ${ }^{15}$

Essa convicção depende da inteligibilidade de um mundo que possa ser capturado por uma receptividade pura. Se expurgarmos a idéia de convergência da convicção de que progredimos em direção à uma receptividade purificada, ficamos apenas com a idéia de que os exercícios de nossas capacidades conceituais atendem melhor a razões na medida em que são aprimoradas por toda sorte de argumentos. Nesse caso, podemos falar de convergência em direção a um pensamento mais balizado em argumentos. $\mathrm{O}$ perigo do estoicismo continua a nos rondar.

Parece que a maneira para que possamos entender a alternativa ao estoicismo - à idéia de que a espontaneidade pode estar agindo sem restrições - envolve uma insistência na conexão intrínseca entre receptividade e espontaneidade. Queremos dizer tanto que a receptividade opera sempre por meio de exercícios de capacidades conceituais quanto que no exercício de qualquer capacidade conceitual há receptividade em operação. ${ }^{16} \mathrm{Ou}$ seja, nesse momento, estamos prontos para rejeitar uma concepção da relação entre pensamento e mundo que favoreça noções de verdade como adequação e aceitar que os exercícios de nossas capacidades conceituais não são apenas exercícios de racionalidade voltados para ela mesma uma vez que elas trazem em si conteúdos do mundo. Esses conteúdos, contudo, não podem ser especificados sem conceitos. Aquilo, portanto, que caracteriza a receptividade em operação em nossos conceitos pode apenas ser caracterizado por outros conceitos; pode ser caracterizado em um tempo futuro, e não em um espaço diferente - para além do escopo de conceitos. Conceitos, se for assim, terão sempre um conteúdo de mundo determinável apenas por meio de conceitos. Pode haver a impressão, contudo, de que conteúdos são determinados (eventualmente) apenas por práticas conceituais e, por conseguinte, de que não são mais do que um exercício - que acontece ao longo do tempo - de espontaneidade.

Essa impressão, me parece, ainda é prisioneira da imagem de mundo que sustenta a possibilidade de uma receptividade pura. Abandonar essa

15 Há muitos modos de pensar nessa convergência. Os bayesianos, por exemplo, entendem que as probabilidades prévias são sempre expressão de nossa subjetividade, mas um repetido e adequado processo de consideração de evidências nos leva a reduzir sua influência e, no limite, torna as probabilidades iniciais irrelevantes. A nossa contribuição fica gradativamente suprimida e, assim, a objetividade é a trajetória do progresso - a ser alcançada no limite. Talvez o modo de pensar no conhecimento encorajado pelo bayesianismo não tenha como deixar de ser tributário dessa maneira de pensar na convergência.

16 É interessante notar que a receptividade parece depender, em qualquer caso, de um ato de reconhecimento, de Anerjennung. Para uma investigação da relação entre reconhecimento e ser movido por razões cf. Bensusan, 2004. 
imagem implica em assumir que nossos conceitos são soberanos, mas não determinam seus conteúdos isoladamente - ainda que não possamos isolar o que seja pura receptividade neles. Se abandonarmos a imagem, podemos dizer simplesmente que o conteúdo de nossos conceitos vêm sempre, em parte, do mundo. O conteúdo de nossos conceitos é sempre determinado por práticas conceituais, algumas das quais não estão explícitas em nossos exercícios de conceitos. O estoicismo só aparece como uma alternativa se imaginarmos o mundo independente de nossos conceitos e de nossa prática de investigação, com o qual não fazemos contato algum.

Uma posição como esta que venho esboçando poderia insistir em que o exercício de capacidades conceituais envolve sempre uma forma de receptividade sem postular um mundo feito de conteúdos pensáveis com respeito aos quais nos esforçamos para que nossos pensamentos sejam adequados. A verdade - e o conteúdo de nossos pensamentos - transcende a simples verificação, porque nossas práticas conceituais nos dirigem de uma forma que torna possível sempre que cometamos erros. ${ }^{17}$ Uma vez que a imagem de um mundo à espera de nossa investigação para se mostrar é abandonada em todas as suas variações, ainda temos o direito de conceber o mundo - aquele no qual pensamos por meio de nossas práticas conceituais e que compartilhamos - e conceber que ele influencia nossos pensamentos. Apenas temos que desistir de toda artimanha para separá-lo de nossas práticas conceituais.

\section{Referências Bibliográficas}

ALLISON, H. E. Kant's transcendental idealism: an interpretation and defense. New Haven: Yale UP, 1983.

BENSUSAN, H. Você pode duvidar de tudo por algum tempo. Você pode duvidar de algumas coisas por todo o tempo. Mas pode você duvidar de tudo por todo o tempo? Principia, v. 6, n. 2, p. 299-313, 2002.

. Depois de anos de deflação galopante, o que sobrou da verdade? Philosophos, v. 8, n. 1, p. 53-68, 2003.

17 Em PU (p. 219), Wittgenstein diz: "A regra, uma vez carimbada com seu significado, traça as linhas às quais deve-se seguir por todo espaço". Ele não parece colocar em questão que isso seja o caso e, no entanto, ele se pergunta de que nos serve isso. O carimbo do significado não é alguma coisa que possamos, por exemplo, enunciar em um adendo à regra - é preciso fazer matemática para determinar alguma coisa matemática. Porém, nossa execução de qualquer regra pode estar errada de acordo com o carimbo do seu significado. Esse carimbo não é, ao contrário do que sugere uma interpretação kripkeana, apenas um reflexo de como nos pomos de acordo para seguir a regra. 
BENSUSAN, H. O pensamento sem estaca zero (A mentalidade externalista e as razões nossas de cada dia). Kriterion, Belo Horizonte, v. 45, n. 110, p. 209-223, 2004. BENSUSAN, H.; PINEDO, M. Holistic knowledge. 2006. (Inédito).

BRANDOM, R. Perception and rational constraint. Philosophy and Phenomenological Research, 58, 2, p. 369-74, 1998.

Some pragmatist themes in Hegel's idealism: negotiation and administration in Hegel's account of the structure and content of conceptual norms. European Journal of Philosophy, v. 7, n. 2, p. 164-189, 1999.

DAVIDSON, D. A coherence theory of truth and knowledge. In: LePORE, E. (Ed.). Truth and interpretation: perspectives on the philosophy of Donald Davidson. Oxford: Blackwell, 1983.

FREGE, G. Thoughts. Mind, LXV, 259, [s.n.t.], 1956. (1 ${ }^{\text {a }}$ ed. Beiträge zur Philosophie des Deutschen Idealismus, 1918).

HEGEL, G. W. F. Lectures on the History of Philosophy [LHP]. California: University of California Press, 1990.

HEGEL, G. W. F. Fenomenologia do espírito [PhG]. Rio de Janeiro: Vozes, 2000.

HORNSBY, J.Truth: the identity theory. In: LYNCH, M. (Ed.). The nature of truth. Cambridge: MIT Press, 2001.

KANT, I. Crítica da faculdade do juízo [KU]. São Paulo: Forense, 1993.

KRIPKE, S. Wittgenstein on rules and private language. Oxford: Blackwell, 1982.

LAMB, D. Language and perception in Hegel and Wittgenstein. Trowbridge: Avebury, 1980.

McDOWELL, J. Wittgenstein on following a rule. Synthese, v. 58, p. 325-363, 1984. . Mind and world. Cambridge: Harvard University Press, 1994.

. Empiricism and the scheme-content dualism. In: HAHN, H. (Ed.). The philosophy of Donald Davidson. Chicago: Open Court, 2000.

WILLIAMS, B. Descartes: the project of pure enquiry. Londres: Penguin, 1978.

WITTGENSTEIN, L. Remarks on the foundations of mathematics [RFM]. Cambridge: MIT Press, 1967.

WITTGENSTEIN, L. Philosophical investigations [PU]. Oxford: Blackwell, 1967. WRIGHT, C. Does philosophical investigations I.258-60 suggest a cogent argument against private language? In: PETTIT; McDOWELL (Ed.). Subject, thought and context. Oxford: Clarendon, 1986.

2002. Human nature? In: SMITH, N. (Ed.). Reading McDowell. Londres: Routledge, 